\title{
Effects of DTPA on Cadmium Accumulation of Galinsoga parviflora
}

\author{
Lijin Lin ${ }^{1, a}$, Zhihui Wang ${ }^{2, b}$, and Ming'an Liao ${ }^{2, c^{*}}$ \\ ${ }^{1}$ Institute of Pomology and Olericulture, Sichuan Agricultural University, Chengdu, Sichuan, China \\ ${ }^{2}$ College of Horticulture, Sichuan Agricultural University, Chengdu, Sichuan, China \\ allj800924@163.com, bwangzhihui318@126.com, Iman@sicau.edu.cn \\ ${ }^{*}$ corresponding author
}

Keywords: DTPA; Cadmium accumulation; Galinsoga parviflora; Chlorophyll content

Abstract: The effects of diethylene triamine pentaacetic acid (DTPA) on cadmium (Cd) accumulation of hyperaccumulator Galinsoga parviflora were investigated through pot experiment. The results showed that the biomass, chlorophyll content of G. parviflora decreased with the increase of DTPA concentrations in the soil. Applying DTPA increased Cd content in G. parviflora, and the maxima of Cd content in shoots of G. parviflora were the dose of $4 \mathrm{mmol} / \mathrm{kg}$ DTPA, which increased by $347.39 \%$ compared with the control. Applying DTPA also increased Cd extraction by $G$. parviflora, and the dose of $4 \mathrm{mmol} / \mathrm{kg}$ DTPA was the best concentration in this experiment to improve Cd extraction by G. parviflora. Therefore, DTPA enhanced the Cd extraction ability of $G$. parviflora from Cd-contaminated soil, and $4 \mathrm{mmol} / \mathrm{kg}$ DTPA demonstrated to be the best dose that could be used to enhance the phytoremediation ability of G. parviflora efficiently.

\section{Introduction}

Hyperaccumulator is the main material for heavy metal phytoremediation [1]. However, the screened hyperaccumulators grow slowly and have small biomass, which are lead to low efficiency of phytoremediation [2]. The chelator is the newly auxiliary phytoremediation material that can improve the bioavailability of heavy metal from soil [3]. When the chelator applying in the soil, the form of heavy metal changes, and increases the bioavailability of heavy metal concentration in the soil, which contributes to heavy metal absorption of hyperaccumulator [4]. When ethylene diamine tetraacetic acid (EDTA) applying in the soil, the available concentration of $\mathrm{Pb}, \mathrm{Cd}, \mathrm{Cu}$ improve, but the proportion of chelation nickel is only $23 \%$ of the full amount nickel [5]. For hyperaccumulator, all of EDTA, diethylene triamine pentaacetic (DTPA) and citric acid promote heavy metals absorption of hyperaccumulator A. corsicum in the low concentrations of heavy metals, and the same chelator is quite different with the effect of different heavy metals [6]. Other studies also have confirmed the chelator can improve the phytoremediation ability of hyperaccumulator [7].

Galinsoga parviflora is a Cd-hyperaccumulator for remedy Cd contaminated soil [8]. However, compared with other high biomass hyperaccumulator [9], the remedy ability of G. parviflora is low, and remains to be improved. Therefore, to enhance the remedy ability to Cd-contaminated soil, the different concentrations of DTPA were applied to treat $G$. parviflora in this study. The aim of the study was to screen DTPA concentration which could enhance the phytoremediation ability of $G$. parviflora, and provide a reference for improving phytoremediation ability of other hyperaccumulators.

\section{Materials and Method}

Materials. The inceptisol soil samples were collected from Ya'an campus farm of the Sichuan Agricultural University $\left(29^{\circ} 59^{\prime} \mathrm{N}, 102^{\circ} 59^{\prime} \mathrm{E}\right)$, China, in March 2014 . The basic properties of the soil were the same as reference [8], and the total Cd content was $0.101 \mathrm{mg} / \mathrm{kg}$. Galinsoga parviflora seedlings with two pairs of euphyllas were collected from the Ya'an campus farm (from uncontaminated soil) in April 2014. 
Experimental Design. The experiment was conducted at the Ya'an campus farm from March to Jun in 2014. The soil samples were air-dried and passed through a 5-mm sieve. Three kilograms of the air-dried soil was weighed into each polyethylene pot $(15 \mathrm{~cm}$ high, $18 \mathrm{~cm}$ in diameter). Cd was added to soils as $\mathrm{CdCl}_{2} \cdot 2.5 \mathrm{H}_{2} \mathrm{O}$ at $10 \mathrm{mg} \mathrm{kg}^{-1}$. The pots were soaked in the Cd solutions for 4 weeks, and then the soil in each pot was mixed with DTPA powder, and the soil moisture was maintained at $80 \%$ of field capacity for 1 week. The DTPA treatments in the experiment were $0,0.5,1,2,4 \mathrm{mmol} / \mathrm{kg}$ [7], and each treatment was replicated three times using a completely randomized design with $10-\mathrm{cm}$ spacing between pots. Four uniform seedlings of G. parviflora were transplanted into each pot and the soil moisture content was maintained at $80 \%$ of field capacity from the time the plants were transplanted into the pots until the time the plants were harvested.

Sample Analysis. After G. parviflora had matured (after $50 \mathrm{~d}$ ), the upper mature leaves of $G$. parviflora were collected to determine the photosynthetic pigment (chlorophyll a, chlorophyll b, total chlorophyll and carotenoid) contents [10]. The plants were then gently removed from the soil. The roots and shoots of $G$. parviflora were harvested and washed with tap water. The roots were immersed in $10 \mathrm{mM} / \mathrm{L} \mathrm{HCl}$ for $10 \mathrm{~min}$ to remove $\mathrm{Cd}$ adhering to the root surface. Then, the treatments and analyses of plants were described as in reference [8].

Statistical Analyses. Statistical analyses were performed using SPSS 13.0 statistical software (IBM, Chicago, IL, USA). Data were analyzed by one-way analysis of variance with least significant difference at a $5 \%$ confidence level.

\section{Results and Discussion}

Biomass of G. parviflora. With the increase of DTPA concentrations in the soil, the root, stem, leaf and shoot biomass of $G$. parviflora decreased (Table 1). The root biomass decreased by $0.58 \%(p>$ $0.05), 2.31 \%(p>0.05), 3.85 \%(p<0.05)$ and $5.39 \%(p<0.05)$ at $0.5,1,2,20$ and $4 \mathrm{mmol} / \mathrm{kg}$ DTPA, respectively, compared with the control, and the shoot biomass decreased by $5.06 \%(p<0.05), 8.82 \%$ $(p<0.05), 12.55 \%(p<0.05)$ and $18.49 \%(p<0.05)$ at $0.5,1,2,20$ and $4 \mathrm{mmol} / \mathrm{kg}$ DTPA, respectively, compared with the control. These results indicate that DTPA could inhibit the growth of G. parviflora, which because of DTPA improves Cd effectiveness in the soil and increases Cd toxicity to G. parviflora [7]. The root/ shoot ratio of G. parviflora had increasing trend with the increase of DTPA concentration, but there was no obvious in low concentrations (Table 1), indicating that $G$. parviflora could increase root proportion to enhance the resistance to $\mathrm{Cd}$ stress.

Table 1 Effects of DTPA on biomass of Galinsoga parviflora

\begin{tabular}{|c|c|c|c|c|c|}
\hline $\begin{array}{c}\text { DTPA concentrations } \\
(\mathrm{mmol} / \mathrm{kg})\end{array}$ & $\begin{array}{c}\text { Roots } \\
(\mathrm{g} / \mathrm{plant})\end{array}$ & $\begin{array}{c}\text { Stems } \\
\text { (g/plant) }\end{array}$ & $\begin{array}{c}\text { Leaves } \\
\text { (g/plant) }\end{array}$ & $\begin{array}{c}\text { Shoots } \\
\text { (g/plant) }\end{array}$ & $\begin{array}{c}\text { Root/ } \\
\text { shoot } \\
\text { ratio }\end{array}$ \\
\hline 0 & $0.519 \pm 0.006 \mathrm{a}$ & $1.425 \pm 0.035 \mathrm{a}$ & $1.284 \pm 0.030 \mathrm{a}$ & $2.709 \pm 0.065 \mathrm{a}$ & 0.192 \\
\hline 0.5 & $0.516 \pm 0.004 \mathrm{a}$ & $1.364 \pm 0.020 \mathrm{~b}$ & $1.208 \pm 0.017 \mathrm{~b}$ & $2.572 \pm 0.037 \mathrm{~b}$ & 0.201 \\
\hline 1 & $0.507 \pm 0.010 \mathrm{ab}$ & $1.334 \pm 0.018 \mathrm{~b}$ & $1.136 \pm 0.013 \mathrm{c}$ & $2.470 \pm 0.031 \mathrm{bc}$ & 0.205 \\
\hline 2 & $0.499 \pm 0.006 \mathrm{~b}$ & $1.258 \pm 0.024 \mathrm{c}$ & $1.111 \pm 0.014 \mathrm{c}$ & $2.369 \pm 0.038 \mathrm{c}$ & 0.211 \\
\hline 4 & $0.491 \pm 0.003 \mathrm{~b}$ & $1.203 \pm 0.014 \mathrm{c}$ & $1.005 \pm 0.007 \mathrm{~d}$ & $2.208 \pm 0.021 \mathrm{~d}$ & 0.222 \\
\hline
\end{tabular}

Photosynthetic Pigment Contents of G. parviflora. When applying DTPA in the soil, the photosynthetic pigment contents of G. parviflora decreased (Table 2), which were consistent with the biomass. With the increase of DTPA concentrations in the soil, the chlorophyll a, chlorophyll b, total chlorophyll and carotenoid contents of $G$. parviflora decreased. The total chlorophyll content decreased by $17.79 \%(p<0.05), 18.01 \%(p<0.05), 26.63 \%(p<0.05)$ and $32.43 \%(p<0.05)$ at 0.5 , 1, 2, 20 and $4 \mathrm{mmol} / \mathrm{kg}$ DTPA, respectively, compared with the control, and the carotenoid content decreased by $19.80 \%(p<0.05), 21.45 \%(p<0.05), 30.86 \%(p<0.05)$ and $35.31 \%(p<0.05)$ at 0.5 , 1, 2, 20 and $4 \mathrm{mmol} / \mathrm{kg}$ DTPA, respectively, compared with the control. The carotenoid can receive the surplus energy of excited chlorophyll molecule, and avoids formatting the singlet oxygen, which 
plays the protective effect of light [11]. DTPA decreased carotenoid contents of G. parviflora suggesting that the damage of $G$. parviflora by light enhanced with the increase of DTPA concentrations in the soil. The chlorophyll $\mathrm{a} / \mathrm{b}$ of G. parviflora decreased when the dose of DTPA was not more than $2 \mathrm{mmol} / \mathrm{kg}$, and increased from the dose of $2 \mathrm{mmol} / \mathrm{kg}$ to $4 \mathrm{mmol} / \mathrm{kg}$ (Table 2). So, under the low concentrations of DTPA, the photosynthesis of G. parviflora could weaken, and with strong photosynthesis under the high concentrations of DTPA.

Table 2 Effects of DTPA on photosynthetic pigment contents of Galinsoga parviflora

\begin{tabular}{|c|c|c|c|c|c|}
\hline $\begin{array}{c}\text { DTPA } \\
\text { concentrations } \\
(\mathrm{mmol} / \mathrm{kg})\end{array}$ & $\begin{array}{c}\text { Chlorophyll a } \\
(\mathrm{mg} / \mathrm{g})\end{array}$ & $\begin{array}{c}\text { Chlorophyll b } \\
(\mathrm{mg} / \mathrm{g})\end{array}$ & $\begin{array}{c}\text { Total } \\
\text { chlorophyll } \\
(\mathrm{mg} / \mathrm{g})\end{array}$ & $\begin{array}{c}\text { Chlorophyll } \\
\mathrm{a} / \mathrm{b}\end{array}$ & $\begin{array}{c}\text { Carotenoid } \\
(\mathrm{mg} / \mathrm{g})\end{array}$ \\
\hline 0 & $1.790 \pm 0.003 \mathrm{a}$ & $0.486 \pm 0.003 \mathrm{a}$ & $2.276 \pm 0.006 \mathrm{a}$ & 3.683 & $0.606 \pm 0.006 \mathrm{a}$ \\
\hline 0.5 & $1.471 \pm 0.040 \mathrm{~b}$ & $0.400 \pm 0.011 \mathrm{~b}$ & $1.871 \pm 0.051 \mathrm{~b}$ & 3.678 & $0.486 \pm 0.017 \mathrm{~b}$ \\
\hline 1 & $1.460 \pm 0.044 \mathrm{~b}$ & $0.406 \pm 0.007 \mathrm{~b}$ & $1.866 \pm 0.051 \mathrm{~b}$ & 3.596 & $0.476 \pm 0.012 \mathrm{~b}$ \\
\hline 2 & $1.313 \pm 0.068 \mathrm{c}$ & $0.357 \pm 0.015 \mathrm{c}$ & $1.670 \pm 0.083 \mathrm{c}$ & 3.675 & $0.419 \pm 0.002 \mathrm{c}$ \\
\hline 4 & $1.214 \pm 0.060 \mathrm{c}$ & $0.324 \pm 0.004 \mathrm{~d}$ & $1.538 \pm 0.064 \mathrm{c}$ & 3.747 & $0.392 \pm 0.009 \mathrm{c}$ \\
\hline
\end{tabular}

Cd Content in G. parviflora. With the increase of DTPA concentrations in the soil, the Cd content in G. parviflora increased compared with the control (Table 3), which was related to DTPA improving available $\mathrm{Cd}$ concentration in the soil [7]. The Cd contents in roots, stems, leaves and shoots of $G$. parviflora increased with the increase of DTPA concentrations in the soil. The Cd content in roots increased by $12.31 \%(p<0.05), 62.11 \%(p<0.05), 111.01 \%(p<0.05)$ and $218.22 \%$ $(p<0.05)$ at $0.5,1,2,20$ and $4 \mathrm{mmol} / \mathrm{kg}$ DTPA, respectively, compared with the control, and the Cd content in shoots increased by $14.79 \%(p<0.05), 101.68 \%(p<0.05), 176.22 \%(p<0.05)$ and $347.39 \%(p<0.05)$ at $0.5,1,2,20$ and $4 \mathrm{mmol} / \mathrm{kg}$ DTPA, respectively, compared with the control. These results indicate that the Cd content increase rate of shoots was higher than that in roots. The translocation factor (TF) of G. parviflora also increased with the increase of DTPA concentrations in the soil, indicating that DTPA promoted Cd transporting from roots to shoots of G. parviflora, which could be benefit to improve the phytoremediation ability of G. parviflora.

Table 3 Effects of DTPA on Cd content in Galinsoga parviflora

\begin{tabular}{|c|c|c|c|c|c|}
\hline $\begin{array}{c}\text { DTPA } \\
\text { concentrations } \\
(\mathrm{mmol} / \mathrm{kg})\end{array}$ & $\begin{array}{c}\text { Roots } \\
(\mathrm{mg} / \mathrm{kg})\end{array}$ & $\begin{array}{c}\text { Stems } \\
(\mathrm{mg} / \mathrm{kg})\end{array}$ & $\begin{array}{c}\text { Leaves } \\
(\mathrm{mg} / \mathrm{kg})\end{array}$ & $\begin{array}{c}\text { Shoots } \\
(\mathrm{mg} / \mathrm{kg})\end{array}$ & TF \\
\hline 0 & $12.35 \pm 0.92 \mathrm{~d}$ & $10.39 \pm 0.86 \mathrm{~d}$ & $13.57 \pm 0.61 \mathrm{~d}$ & $11.90 \pm 0.74 \mathrm{~d}$ & 0.96 \\
\hline 0.5 & $13.87 \pm 0.33 \mathrm{~d}$ & $12.04 \pm 0.74 \mathrm{~d}$ & $15.48 \pm 0.74 \mathrm{~d}$ & $13.66 \pm 0.75 \mathrm{~d}$ & 0.98 \\
\hline 1 & $20.02 \pm 1.39 \mathrm{c}$ & $20.80 \pm 0.99 \mathrm{c}$ & $27.75 \pm 1.71 \mathrm{c}$ & $24.00 \pm 1.32 \mathrm{c}$ & 1.20 \\
\hline 2 & $26.06 \pm 1.05 \mathrm{~b}$ & $26.64 \pm 1.22 \mathrm{~b}$ & $39.92 \pm 1.53 \mathrm{~b}$ & $32.87 \pm 1.39 \mathrm{~b}$ & 1.26 \\
\hline 4 & $39.30 \pm 0.99 \mathrm{a}$ & $42.33 \pm 2.35 \mathrm{a}$ & $66.30 \pm 2.40 \mathrm{a}$ & $53.24 \pm 2.40 \mathrm{a}$ & 1.35 \\
\hline
\end{tabular}

The translocation factor (TF) is defined as Cd content in shoot/ Cd content in root.

Cd Extraction by G. parviflora. The Cd extraction by G. parviflora increased when applied DTPA in the soil compared with the control (Table 4). With the increase of DTPA concentrations in the soil, the Cd extractions by roots, stems, leaves, shoots and whole plant increased. The Cd extraction by roots increased by $11.70 \%(p>0.05), 58.35 \%(p<0.05), 102.81 \%(p<0.05)$ and $201.09 \%(p<0.05)$ at $0.5,1,2,20$ and $4 \mathrm{mmol} / \mathrm{kg}$ DTPA, respectively, compared with the control; the Cd extraction by shoots increased by $8.97 \%(p>0.05), 83.90 \%(p<0.05), 141.72 \%(p<0.05)$ and $264.72 \%(p<0.05)$ at $0.5,1,2,20$ and $4 \mathrm{mmol} / \mathrm{kg}$ DTPA, respectively, compared with the control; the Cd extraction by whole plant increased by $9.42 \%(p>0.05), 79.66 \%(p<0.05), 135.14 \%(p<0.05)$ and $254.17 \%(p<0.05)$ at $0.5,1,2,20$ and $4 \mathrm{mmol} / \mathrm{kg}$ DTPA, respectively, compared with the control. Therefore, DTPA can effectively improve phytoremediation ability of $G$. parviflora, which was consistent with the other studies [7]. 
Table 4 Effects of DTPA on Cd extraction by Galinsoga parviflora

\begin{tabular}{|c|c|c|c|c|c|}
\hline $\begin{array}{c}\text { DTPA } \\
\text { concentrations } \\
(\mathrm{mmol} / \mathrm{kg})\end{array}$ & $\begin{array}{c}\text { Roots } \\
(\mu \mathrm{g} / \mathrm{plant})\end{array}$ & $\begin{array}{c}\text { Stems } \\
(\mu \mathrm{g} / \mathrm{plant})\end{array}$ & $\begin{array}{c}\text { Leaves } \\
(\mu \mathrm{g} / \mathrm{plant})\end{array}$ & $\begin{array}{c}\text { Shoots } \\
(\mu \mathrm{g} / \mathrm{plant})\end{array}$ & $\begin{array}{c}\text { Whole plant } \\
(\mu \mathrm{g} / \mathrm{plant})\end{array}$ \\
\hline 0 & $6.41 \pm 0.41 \mathrm{~d}$ & $14.81 \pm 0.86 \mathrm{~d}$ & $17.42 \pm 0.38 \mathrm{~d}$ & $32.23 \pm 1.24 \mathrm{~d}$ & $38.64 \pm 1.65 \mathrm{~d}$ \\
\hline 0.5 & $7.16 \pm 0.11 \mathrm{~d}$ & $16.42 \pm 0.77 \mathrm{~d}$ & $18.70 \pm 0.63 \mathrm{~d}$ & $35.12 \pm 1.40 \mathrm{~d}$ & $42.28 \pm 1.51 \mathrm{~d}$ \\
\hline 1 & $10.15 \pm 0.50 \mathrm{c}$ & $27.75 \pm 0.94 \mathrm{c}$ & $31.52 \pm 1.59 \mathrm{c}$ & $59.27 \pm 2.53 \mathrm{c}$ & $69.42 \pm 3.03 \mathrm{c}$ \\
\hline 2 & $13.00 \pm 0.38 \mathrm{~b}$ & $33.51 \pm 0.89 \mathrm{~b}$ & $44.35 \pm 1.13 \mathrm{~b}$ & $77.86 \pm 2.02 \mathrm{~b}$ & $90.86 \pm 2.40 \mathrm{~b}$ \\
\hline 4 & $19.30 \pm 0.39 \mathrm{a}$ & $50.92 \pm 2.23 \mathrm{a}$ & $66.63 \pm 1.95 \mathrm{a}$ & $117.55 \pm 4.17 \mathrm{a}$ & $136.85 \pm 4.55 \mathrm{a}$ \\
\hline
\end{tabular}

\section{Conclusions}

Applied DTPA in the soil decreased the biomass of $G$. parviflora with the increase of DTPA concentrations. The chlorophyll a, chlorophyll b, total chlorophyll and carotenoid contents also decreased with the increase of DTPA concentrations in the soil. DTPA promoted the Cd absorption of G. parviflora from soil, and increased Cd content and Cd extraction of G. parviflora. The maximum of Cd extraction by G. parviflora was at $4 \mathrm{mmol} / \mathrm{kg}$ DTPA. Therefore, DTPA can effectively improve phytoremediation ability of G. parviflora, and could be applied in the field.

\section{References}

[1] R. Datta, D. Sarkar, Effective integration of soil chemistry and plant molecular biology in phytoremediation of metals, Environmental Geosciences 11 (2004) 53-63.

[2] E. Maestri, M. Marmiroli, G. Visioli, N. Marmiroli, Metal tolerance and hyperaccumulation: Costs and trade-offs between traits and environment, Environmental and Experimental Botany 68 (2010) 1-13.

[3] X.Y. Liao, T.B. Chen, X.L. Yan, C.J. Nie, Enhancement of heavy metal removal in phytoremedication of soils contaminated with heavy metals, Acta Scientiae Circumstantia, 27 (2007) 881-893 (In Chinese).

[4] M.W.H. Evangelou, M. Ebel, A. Schaeffer, Chelate assisted phytoextraction of heavy metals from soil: effect, mechanism, toxicity and fate of chelating agents, Chemosphere, 68 (2007) 989-1003.

[5] C. Sahut, G. Geniaut, M.P. Lillo, Phytoremediation of metals contaminated dredged sediments: use of synthetic chelates in metals phytoextraction, Journal de Physique IV (Proceedings), 107 (2003): 1169-1171.

[6] D.J. Zhao, Research of Chelate-Induced Technology Applied in Phytoremediation of Heavy Metal Contaminated Soils (Master Thesis), Sun Yat-Sen University, Guangzhou, China, 2004 (In Chinese).

[7] H.Y. Zhao, L.J. Lin, Q.L. Yan, Y.X. Yang, X.M. Zhu, J.R. Shao, Effects of EDTA and DTPA on lead and zinc accumulation of ryegrass, Journal of Environmental Protection 2 (2011) 932-939.

[8] L.J. Lin, Q. Jin, Y.J. Liu, B. Ning, M.A. Liao, L. L, Screening of a new cadmium hyperaccumulator, Galinsoga parviflora, from winter farmland weeds using the artificially high soil cadmium concentration method, Environmental Toxicology and Chemistry 33 (2014) 2422-2428.

[9] S.H. Wei, Q.X. Zhou, X. Wang, K.S. Zhang, G.L. Guo, Q.Y. Ma Lena, A newly-discovered Cd-hyperaccumulator Solanum nigrum L., Chinese Science Bulletin 50 (2005) 33-38.

[10] Z.B. Hao, J. Cang, Z. Xu, Plant Physiology Experiment, Harbin Institute of Technology Press, Harbin, China, 2004 (In Chinese).

[11] C.P. Sun, J.Z. Zhang, S.J. Duan, Introduction of Free Radical Biology, University of Science and Technology of China Press, Hefei, China, 1999 (In Chinese). 